\title{
The cognitive approach as a challenge in foreign language teaching
}

\author{
Miroslava Tsvetkova*
}

\begin{abstract}
The cognitive approach in foreign language teaching attracts young learners' attention to the topic, enhances and facilitates the comprehension of grammar and language, increases students' motivation, as well as helps students to memorize new vocabulary and structures.

The aim of the article is to persuade teachers that the cognitive approach applied in the lesson provokes a change in the dynamics of the language classroom and serves as a motivational tool for students. An author's cognitive model is an example for the easy comprehension and production of the difficult English present progressive construction by Bulgarian young learners.

The model is discussed within the generativist framework and the usage-based theories as the pre-linguistic conditions take an important part in it. The taxonomy of constructions, which is also part of the model, focuses on the relationship between the English present progressive construction and the constructions preceding it.
\end{abstract}

Key words: language acquisition, FLT, cognitive approach, taxonomy of constructions.

\section{Introduction}

Foreign language acquisition has become one of the most dynamic and promising areas of research in cognitive science. Contemporary theoretical and empirical studies have convinced more scientists that a thorough research on the process of learning a foreign language is a way of understanding the cognitive processes in language acquisition. The article focuses on the challenge of using the cognitive approach in the language classroom and given the multiplicity of perspectives on learning, an appropriate unit of analysis should be identified. It is the acquisition of the grammatical construction of present progressive tense in English by Bulgarian young learners (I-IV grade) analysed in the author's cognitive model. Arising from the fact that learners are not motivated enough to learn a language that they don't use in everyday life, it is the teacher's choice of an appropriate approach that takes an important role because it has the power to foster the language acquisition.

The aim of the article is to persuade teachers that the cognitive approach applied in the lesson provokes a change in the dynamics of the language classroom and serves as a motivational tool for students. Teachers should focus less on general

* University of Shumen, Department of English Studies, Shumen, Bulgaria 
approaches to English language teaching and more on meeting the challenges that they have identified.

This article is part of a larger study, which investigated the applicability of the author's cognitive model in teaching young learners.

Language is a complex cognitive activity, so pre-linguistic conditions take an important part in its acquisition. The leading power of the author's cognitive model is just on the relationship between the grammatical construction and the vocabulary that has originated long before they have been taught. When children start exploring the world around them, they first try to recognize objects and processes, to distinguish and name them. Children use simple words at this stage so they build a repertoire of words and later on they add prefixes, suffixes and endings. A similar phenomenon is observed in learning a second language, too. When constructing an utterance, speakers are assumed to retrieve individual lexical items in accordance with the syntactic rules governing the combination of words in sequence. In a generativist framework, the auxiliary system is assumed to be purely structural, devoid of semantic or functional content and therefore difficult to learn in principle (Chomsky 1957).

The cognitive approach to acquiring the English present progressive construction facilitates the comparison between the familiar and the new knowledge, grammatical rules comprehension, memorization and use of language. The cognitive stress is on using a model with high cognitive value, which develops and improves logical thinking and encourages imagination in its implementation. Thus, it aims to convert students from passive recipients to active constructors of knowledge. Meanwhile, knowledge is obtained through individual participation and contact with the contents (information) rather than by imitation or repetition, as in traditional didactic memory-based models (Ivanov 2005, 3).

\section{Theoretical approaches to language acquisition (Theoretical prerequisites)}

A key role in this article plays the differentiation of the meanings of the term cognitive approach. To distinguish the two cognitive theories and avoid the confusion in the article using the word "cognitive", the author uses "structural approach" in Chomsky's theory as the generative theory is described as structural and mentalistic, while retaining the concept "cognitive approach" for the cognitive-functional theory.

As it was already mentioned, there are basically two theories about the way children acquire a language. According to the generative grammar (Chomsky 1968) all children have an innate universal grammar, which is abstract enough to structure any language. Thus the acquisition consists of two processes: (1) 
acquisition of all the words, idioms and structures of the target language including the construction of the present progressive tense be +Ving, and (2) associating the acquired language with the universal grammar. The grammatical level is the level of form because relations between the linguistic items are applied according to a set of rules specific to different languages. Therefore, each unit will be considered in more general terms, as a process or as a grammatical category.

A modern theory of language, the usage-based theory, suggests that children initially build up their language through very concrete constructions based on individual words or frames from the speech they hear and use. Basically this means, according to Tomasello (2003) the developer of the theory, that children learn language from their linguistic knowledge and experiences and a language structure emerges from language use.

In cognitive linguistics, linguistic facts are often explained beyond the linguistic reality and they gain nonlinguistic nature - social, cultural, psychological, etc. Language activity is regarded as one of the models of cognition and it is based on cognitive abilities which are not linguistic but create prerequisites for language. As an example, Langacker's Cognitive grammar is an interesting theoretical account of cognitive processing reflected in linguistic structure. A fundamental principle in this approach is the idea that it is not actually suggested to focus on language separately from the cognitive activity of memory, attention, social contacts of people or any experience. The very nature of language fits the extralinguistic reality - both mental and social (Langacker 1987, 1991; Lacoff 1987). According to some representatives in this field knowledge of the structure of grammar is built step by step, the way the words in the language are used. Input is the starting point and students acquire linguistic items and structures for shapes and sizes, for different levels of abstraction and just then they produce their own utterances, linking some of them to express their communicative intent (Tomasello 2003).

The usage-based theory postulates several principles of language use, which are illustrated in Fig.1.

In the usage-based framework, the emphasis is on structures as basic units of language (Langacker 1987; Goldberg 1995; Croft 2001). It states that children acquire a language only through common cognitive principles such as deriving a pattern and categorization. So, grammatical categories such as noun, verb and auxiliary are accepted to exist only to a level that can be derived from input (Croft 2001; Langacker 1991). The framework uses an elaborate system of graphic schemata to facilitate understanding on the part of the student of how grammar works. 


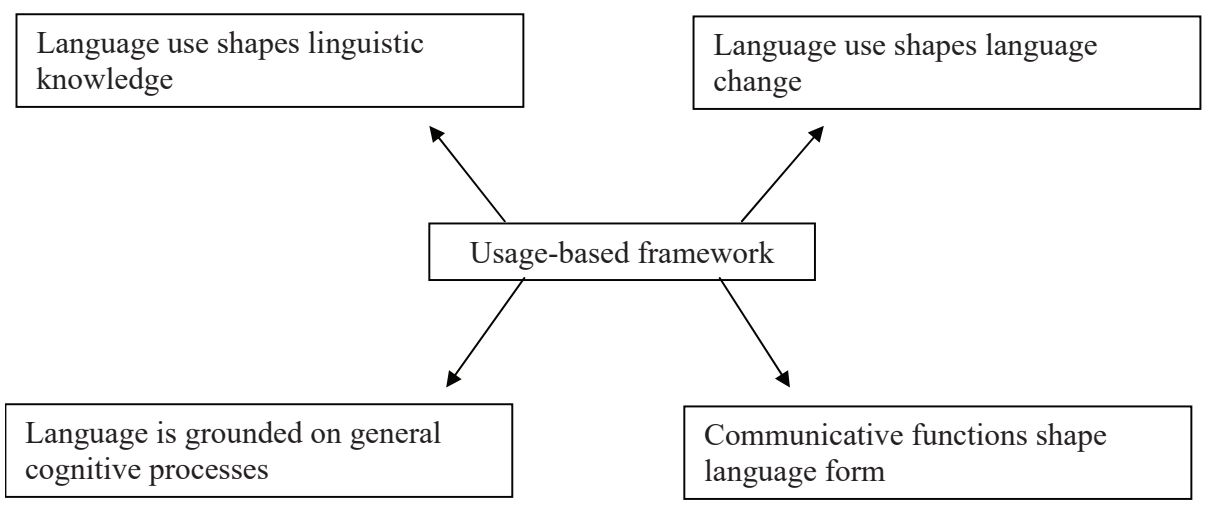

Fig. 1. Principles of language use according to the usage-based framework.

Within the generativist framework, children need pre-given knowledge of grammar, and thus their task in language acquisition is to map the words of their target language onto pre-existing abstract categories (Pinker 1989). The fundamental theoretical point from a construction grammar perspective is that the most basic phenomenon of language is people making utterances in particular situations, using concrete pieces of language. Thus, from a usagebased perspective linguistic constructions are things that children learn and construct out of the language they hear around them using the same cognitive and social-cognitive skills that they use in other areas of their lives. As Tomasello (2003: 99) points out:

When people repeatedly use the same particular and concrete linguistic symbols to make utterances to one another in "similar" situations, what may emerge over time is a pattern of language use, schematized in the minds of users as one or another kind of linguistic category or construction. As opposed to linguistic rules, conceived of as algebraic procedures for combining symbols that do not themselves contribute to meaning, linguistic categories and constructions are themselves meaningful linguistic symbols - since they are nothing other than the patterns, in which meaningful linguistic symbols are used to communicate.

As the properties of tense and agreement are assumed to be innately specified, children's early use of auxiliaries is considered by many researchers to reflect underlying, adultlike grammatical competence (Valian 1991; Wexler 1994; Rice et al. 1998).

An additional perspective on these claims comes from an examination of adults who are assumed to store individual utterances or specific lexical constructions as well as more abstract schemas, for example a general pattern for subjectauxiliary inversion.

So the linguistic knowledge of adults consists of a network of hierarchical 
structures representing cognitive abstractions, although syntactic and semantic connections between structures have different representation in different grammatical frameworks (Croft 2001).

The theories of cognitive development of children often differ in meaning that is attributed to age and inner factors or on the other hand, on experience and learning. The nativist theories like Chomsky's theory for specific mechanisms for working out the rules of language (language acquisition device - LAD) (Chomsky 1968) put an emphasis on the innate aspects of development. According to Chomsky, infants acquire grammar because it is a universal property of language and that is the reason he has coined these fundamental grammatical ideas that all humans have as universal grammar.

According to Tomasello's functional-based model (2000), however, the early language production of children consists of patterns associated with specific lexical structures.

\section{A linguo-didactic model based on the cognitive approach (Descriptive application)}

Classroom practices in foreign language acquisition continue to rely on traditional methodologies, paying little attention to whatever theoretical insights cognitive science can offer.

Anyone having some experience of learning English outside the target language environment will agree that one of the most difficult parts of the English grammar is the verb, its forms and functions. Traditional grammars are not particularly explicit about the rules and mechanisms in each case.

There are several psychological approaches that attempt to define human behaviour, and one of these is the cognitive approach. As is suggested by its name, this approach focuses solely on the internal and invisible processes that allow people to react to external stimuli. Specifically, it looks at how people process information that they get from their senses and how they respond to these information.

Children usually become bored when teachers use traditional practices to teach grammar. Given the age, the value of explicit grammar teaching might be questioned. That is why the traditional view of the purpose of grammar has lately been restated by some modern trends in linguistics. In particular, scholars belonging to these trends pay much attention to artificially constructing and analysing incorrect utterances with the aim of a better formulation of the rules for the construction of correct ones. But their examples and deductions, too, are often at variance with real facts of lingual usage. The starting point of this study is also the error. Some of the students' troubles in the acquisition of the present 
progressive construction come from the features of the target language. On the other hand, grammar rules are not introduced because of the specifics of foreign language teaching to young learners. The fact that children at this age already have logical thinking and it lets them easily find the rules and regulations, provoked the idea to use the cognitive approach to grammar acquisition. It confirms that there is strong relationship between the main cognitive and linguistic structures.

The linguo-didactic model based on the cognitive approach, together with its visualization motivates young learners, enhances and facilitates the comprehension of grammar and language as it concerns their emotions and curiosity. The fact students can easily identify and produce the grammatical construction in the process of communication proves the effectiveness of the ongoing cognitive processes.

The reason why the cognitive model is presented as an example in the study is to outline the main parameters the approach can follow as well as to show the results teachers can expect if they apply the cognitive approach in the classroom.

Two aspects of the process of effective learning should be noted - one of them is the emphasis on the intralanguage relations, while the other point is the interlanguage influence.

The linguistic aspect of the cognitive model is based on Chomsky's generative theory and the cognitive-functional approach, namely Tomasello's usagebased theory (Tomasello 2003), Croft's construction grammar (Croft 2001) and Goldberg's cognitive grammar (Goldberg 1995; Langacker 1987, 1991). It reveals the cognitive features of linguistic items (be+Ving construction). The main principle is that learners use the language relying explicitly on cognitive skills that they are known to possess. The methodological aspect of the study of the English present progressive construction is not a point of discussion and will not be presented in this article.

The main focus of the model is on the way linguistic and non-linguistic experiences interact to build a productive system of language, which is a question in cognitive linguistics.

The construction is an inseparable unity of form and meaning from a linguistic point of view. The relations whole-part, part-whole as well as the contracted forms (i.e. he's) are presented in a cognitive aspect. This blurs the line between the items (words and parts) and confirms the inseparable unity of parts.

Language and perception are deeply interrelated. We can describe what we perceive using words. Thus nonlinguistic perception influences the linguistic behaviour and language acquisition and the way in which the world is construed 
on particular occasions may have an impact on how language is learned. Specific perceptual mechanisms or categories may be prerequisites for the acquisition of specific words or structures. Everybody's experience is different from that of the others. Everybody builds his own vocabulary and that is the reason why there are various hues in the meanings of the words.

In her work, Young learners' second language visual literacy practices, Marina Arif (www) says that in order to be effective communicators in today's world, children need to be able to interpret, create and select images to convey a range of meanings. In addition, cognitive growth will be stimulated if a balance between verbal and visual experiences is created (Paivio 2006).

The visualisation of the model is an example from the non-linguistic world and it grounds on knowledge and experience. It represents mainly activities in progress, at the moment of speaking in particular, and gives the opportunity to explain the construction in questions and interrogative sentences, too. Each part symbolises a different grammatical item. The cognitive taxonomy of constructions, which is also part of the model, comes to the fore here to make the comprehension easier. It is focusing on the relationship between the English present progressive construction and the constructions preceding it. The author is talking about a tense but it is important to mention the argument that it is part of a construction that resembles a unity of several constructions in hieratical relations with other English constructions.

The same visualized situations can be applied in the contracted forms, too, subject-auxiliary, on the one hand, and auxiliary-negative particle, on the other hand. The relationship between the parts is very important again.

Language and perception are deeply interrelated. We can describe what we perceive using words. Thus, non-linguistic perception influences the linguistic behaviour and language acquisition and the way, in which the world is construed on particular occasions, may have an impact on how language is learned. Specific perceptual mechanisms or categories may be prerequisites for the acquisition of specific words or structures. Everybody's experience is different from that of the others.

For some cognitive linguists, Langacker (1987) and Croft (2000, 78), grammar is a mapping between form and function, and they argue that the functional role of grammatical patterns is concerned with non-linguistic psychological processes such as visual scanning and imagery as well as with psychological dimensions such as colour and depth. The learner of a language needs access to a relatively direct path from perceptual mechanisms to language learning mechanisms so that such relationships can be acquired, and grammatical structures and words can only be learned once the psychological processes and categories are in place. 
In support to the cognitive model researchers, Kemp and Dayton (1985) among them, claim that visuals aid in motivation and maintaining attention by adding variety and making the lesson more interesting.

Other researchers, Joyce and Reder (www), make a similar point in relation to visualisation: "Pictures are more perceptually rich than words, and this visual distinctiveness lends them an advantage in memory. To the extent that subjects also encode the stimulus as a verbal label, subjects have two codes for pictures: in addition to the perceptual features of the stimulus such as colour, shape, and texture, subjects also store a verbal label (similar to the representation for a studied word), that enriches the memory trace and provides redundancy. Picture illustrations are included in textbooks, for example, because they corroborate text and are often more effective than text alone for problem-solving transfer."

It is believed that a child's visual comprehension develops earlier than verbal comprehension (Barry 1997). Piaget and Inhelder (2000) state that because young children have little knowledge of the living world and developing conceptions, they need a large amount of visual information to represent their thoughts. This may explain why their information needs are distinctly pictorial rather than textual.

The beneficial effects of the visual materials and the reasons why pictures facilitate comprehension and learning are explained by Levin and Mayer (1993). They proposed some principles called the seven "Cs" for explaining the "whys" of picture facilitation. In particular, they suggest that pictures improve students' learning from text because they make the text more concentrated (focused, with respect to directing a reader's attention), compact/concise ("a picture is worth a thousand words"), concrete (the representation function), coherent (the organization function), comprehensible (the interpretation function), correspondent (relating unfamiliar text to a reader's prior knowledge), and codable (the mnemonic transformation function).

In contrast to the Levin and Mayer's review (1993), which focused on illustrationtext characteristics and correspondence, Bransford's model focuses on the learner's characteristics and learning activities, too. Learner's characteristics include the age of the learner, the learner's reading ability, and the learner's visual literacy (i.e., one's ability to "read" pictures).

The author suggests the approach as a way to let the young learners acquire the grammatical construction not as a unity of rules and exceptions that should be learnt by heart but rather as a presentation of language, in which the parts of the construction, the relationship of each part to the whole and the meaning of the construction as a whole, are acquired cognitively.

Although, from generative point of view, the difficulties young learners have, come from the differences between the native and the target language and the 
cognitive-functional perspective considers the main principles of knowledge are responsible for the acquisition of the construction, both theories focus on the opposition part-whole. The difference comes from the fact that Chomsky's theory stresses on parts and it does not explain how the whole construction is acquired while the cognitive-functional theory emphasises on main cognitive principles of semantisation and conceptualisation.

The cognitive approach can also be applied to using modal constructions, perfect aspect and even passive voice. Once young learner acquire the present progressive construction, in which the auxiliary be is the main item, they will be able to use it in other constructions. The leading factors of the approach are repeatedness, intra- and interlanguage transfer of knowledge about the use of the auxiliary be in present progressive, passes through present simple and finally takes part in constructions with other modal verbs, have and passive voice.

\section{Conclusion}

This article has highlighted the parameters of the cognitive model - a unity of a whole consisting of parts, repeatedness, contextuality, taxonomic hierarchy of constructions preceding it, and a visualisation, which helps the young learners' cognitive skills to get themselves to the abstract and symbolic meaning of the construction.

Building a model of a grammatical item requires completion, i.e. each element must receive an adequate and consistent performance in a general model. Unfortunately, the suggested description of the English grammatical construction, reflecting the author's experience, cannot be regarded as exhaustive in any point of detail. Such a complex and comprehensive model in grammar cannot be achieved anyway, because language is a complex system that is influenced by various linguistic and extralinguistic factors. It just aims to supply the students with approaches that will enable them to judge their own questions of diverse grammatical intricacies and bring forth a steady habit of trying to see into the deeper implications underlying the outward appearances of lingual correlations bearing on grammar (Bloh 1983).

Using the theory of cognitive linguistics as its base, the paper shows that linguistic and non-linguistic experiences interact to build a productive system of language.

The approach presented in this paper may serve as guidelines for teachers when implementing the cognitive approach in teaching, as they want their students to fully concentrate on the lesson and foster their learning. When teachers know how to grab the students' attention, they can provide a friendly and interesting atmosphere for the students to learn. This will encourage them to find their own initiative to learn in order to improve their own understanding towards the 
topic.

The aim of the paper is simply to outline the main applications of the cognitive approach in FLT and we do not claim that it is exhaustive in this goal. The topic could be further explored by applying the cognitive approach to adult learners.

\section{References}

Arif 2009. Arif M. "Young learners' second language visual literacy practices". Available online at $<$ http://www.inter-disciplinary.net/wp-content/uploads/2009/06/mohdarifpaper. pdf $>$. Last accessed 19.11.2016.

Barry 1997. Barry A. M. Visual intelligence, perception, image, and manipulation in visual communication. Albany, NY: State University of New York Press, 1997.

Bloh 1983. Bloh M. Ya. Teoreticheskaya gramatika angliyskovo yazyika. Textbook, 1983. Available online at <http://www.homeenglish.ru/Textblokh.htm>. Last accessed 19.11.2016.

Chomsky 1957. Chomsky N. Syntactic structure. The Hague: Mouton, 1957.

Chomsky 1968. Chomsky N. Language and mind. New York: Harcourt, Brace and World, 1968.

Croft 2000. Croft, W. Explaining Language Change: An Evolutionary Approach. England Pearson Education Limitted, 2001, 78.

Croft 2001. Croft W. Radical construction grammar. Oxford, England: Oxford University Press, 2001.

Goldberg 1995. Goldberg A. Constructions: A Construction Grammar Approach to Argument Structure. Chicago: University of Chicago Press, 1995.

Ivanov 2005. Ivanov I. Interaktini metodi za rabota $v$ multikulturna sreda.. Narachnik. Shumen, 2005.

Kemp, Dayton 1985. Kemp J. E., D. K. Dayton. Planning and Producing Instructional Media. Harper and Row, 1985.

Lacoff 1987. Lakoff G. Women, Fire, and Dangerous Things: What Categories Reveal about the Mind. Chicago: The University of Chicago Press, 1987.

Langacker 1987. Langacker R. Foundations of Cognitive Grammar. (vol.1). Stanford, CA: Stanford University Press, 1987.

Langacker 1991. Langacker R. Foundations of Cognitive Grammar. (vol.2). Stanford, CA: Stanford University Press, 1991.

Levin, Mayer 1993. Levin J. R., R. E. Mayer. Understanding Illustrations in Text. In Brinton B.K., Woodward A., M. Brinkley (eds.). Learning from textbooks. Erlbaum, 1993. 95-113.

Oates, Reder web. Oatesa J. M., L. M. Reder. "Memory for Pictures: Sometimes a Picture is not Worth a Single Word". Available online at $<$ http://memory.psy.cmu.edu/ publications/10Oates_Reder.pdf $>$. Last accessed 16.11.2016.

Paivio 2006. Paivio, A. "Dual Coding Theory and Education". Available online at $<$ http://moodle1315.up.pt/pluginfile.php/147313/mod_book/intro/paivio.pdf >. Last accessed 23.11.2016. 
Piaget, Inhelder 2000. Piaget J., B. Inhelder. The Development of Perception. New York: Basic Book, 2000.

Pinker 1989. Pinker S. Learnability and Cognition. Cambridge, MA: MIT Press, 1989.

Rice et al. 1998. Rice M., Wexler K., S. Hershberger. "Tense over Time: The Longitudinal Course of Tense Acquisition in Children with Specific Language Impairment”. Journal of Speech, Language, and Hearing Research 41, 1998. 1412-1431.

Tomasello 2000. Tomasello M. "Do Young Children have Adult Syntactic Competence?" Cognition 74. 2000. 209-253.

Tomasello 2003. Tomasello M. Construction a language: A usage-based theory of language acquisition. Cambridge, MA: Harvard University Press, 2003.

Valian 1991. Valian V. "Syntactic Subjects in the Early Speech of American and Italian Children". Cognition 40, 1991. 21-81.

Wexler 1994. Wexler K. "Optional Infinitive, Head Movement and the Economy of Derivations". In Hornstein N., D. Lightfoot (eds.). Verb Movement. New York: Cambridge University Press, 1994. 